\title{
On the mechanical properties of hierarchically structured biological materials
}

\author{
Sabine Bechtle, Siang Fung Ang, Gerold A. Schneider \\ Institute of Advanced Ceramics, Hamburg University of Technology, Denickestr. 15, D-21073 \\ Hamburg, Germany
}

\begin{abstract}
Many biological materials are hierarchically structured which means that they are designed from the nano- to the macroscale in a sometimes self-similar way. There are lots of papers published including very detailed descriptions of these structures at all length scales however, investigations of mechanical properties are most often focused on either nanoindentation or bulk mechanical testing characterizing properties at the smallest or largest size scale. Interestingly, there are hardly any investigations that systematically interconnect mechanical properties of different length scales. Nevertheless there are often conclusions drawn like the one that "biological materials exhibit their excellent mechanical properties due to their hierarchical structuring". Thus, we think there is a gap and discrepancy between the detection and description of biological structures and the correlated determination and interpretation of their mechanical properties. Hence, in this paper we order hierarchically structured biological materials with high mineral content according to their hierarchical levels and attribute measured mechanical properties to them. This offers the possibility to gain insight into the mechanical properties on different hierarchical levels even though the entire biological materials were tested. On the other hand we use data of one material, namely enamel, where mechanical properties were measured on every length scale. This kind of data analysis allows to show how a theoretical model developed by Huajian Gao and co-workers can be used to get closer insights into experimental data of hierarchically structured materials.
\end{abstract}




\section{Introduction}

Many mineralized biological materials are hierarchically structured beginning at the smallest length scale with mineral nano-fibers, -platelets, or -spheres which are embedded within proteins and are arranged into superordinate structures at larger size levels. Hierarchical structuring can embrace up to for example 7 levels of hierarchy [1] within bone where the largest structural elements reach length scales of millimetres [1]. Very detailed descriptions of the hierarchical structures of several biological materials such as shells, bone, teeth, sponge spicules, or wood can be found in three recently published review articles [2-4]. Table 1 gives a short overview of the structures of some selected mineralized biological materials which are discussed in this paper.

In general, investigations of mechanical properties of biological materials can be divided into two major groups, namely indentation and miniaturized bulk mechanical testing studies. On the one hand, mechanical properties as elastic modulus, hardness, and toughness are determined via indentation methods whereas nano-indentation recently seems to supersede micro-indentation methods. Table 2 summarizes data that was determined via indentation for the biological materials introduced in Table 1. As the issue of this paper is to understand and discuss the mechanical properties of biological materials in regard to their hierarchical structuring, the data presented were allocated according to the hierarchical level classification presented in Table 1. As can be seen, indentation techniques are appropriate to determine parameters for small structural elements at the nano- and micrometer scale. On the other hand, much effort is done to miniaturize bulk mechanical testing techniques to realize compression, bending or tensile experiments for elastic modulus, strength and toughness determination of biological materials. Several problems have to be coped with in doing so as both the sample preparation of tiny specimens (which for toughness measurements in addition have to be notched) out of thin and curvy shells (e.g. nacre, conch shell) or thin coatings (e.g. enamel) is quite difficult as well as experimental setups for mechanical testing of such small samples (size scale of millimetres) is quite uncommon and some new techniques had to be developed as for example an inset-CT sample configuration [5] or micro-tensile test setups [6,7]. Nevertheless, bulk elastic modulus, toughness and strength data are available now for many biological materials tested in different modes of loading. 
Table 1: Overview of selected biological materials with a brief description of their hierarchical structure. All these materials are built from the bottom up with the first composite level consisting of mineral platelets, fibers or spheres embedded within a protein phase. The levels of hierarchy are counted here from this first mineral-protein composite level up to the bulk. For more information concerning the specific material structures please see the cited literature.

\begin{tabular}{|c|c|c|c|}
\hline Material & $\begin{array}{l}\text { Mineral } \\
\text { Content } \\
{[\text { vol\%] }}\end{array}$ & Stucture & $\begin{array}{c}\text { Levels of } \\
\text { Hierarchy }\end{array}$ \\
\hline $\begin{array}{c}\text { Nacre } \\
{[3,20-22]}\end{array}$ & 95 & $\begin{array}{l}\text { Aragonite nano-grains are glued } \\
\text { together to form nano-platelets (1) } \\
\text { which are staggered into a brick-and- } \\
\text { mortar like structure, enveloped by } \\
\text { proteins (2) }\end{array}$ & 2 \\
\hline$\underset{[23]}{\text { Enamel }}$ & 85 & $\begin{array}{l}\text { Hydroxyapatite-nano-fibers (1) are } \\
\text { bundled together to micro-fibers ('rods'; } \\
\text { 2) which are partially arranged in a } \\
\text { superordinate decussated structure (3) }\end{array}$ & 3 \\
\hline $\begin{array}{c}\text { Sponge Spicule } \\
{[8,13,24,25]}\end{array}$ & 89 & $\begin{array}{l}\text { Hydrated silica nano-spheres (1) are } \\
\text { arranged into lamellae (2) which are } \\
\text { arranged concentrically around a central } \\
\text { cylinder (3) }\end{array}$ & 3 \\
\hline $\begin{array}{c}\text { Dentin } \\
{[23]}\end{array}$ & 45 & $\begin{array}{l}\text { Collagen fibrils are reinforced by } \\
\text { hydroxyapatite nano-platelets (1) and } \\
\text { form a network-like structure (2) around } \\
\text { the dentinal tubules which are } \\
\text { cylindrically shaped and surrounded by } \\
\text { a highly mineralized cuff (3) }\end{array}$ & 3 \\
\hline $\begin{array}{l}\text { Conch Shell } \\
{[26,27]}\end{array}$ & 99 & $\begin{array}{l}\text { Layered, ply-wood like structures: } \\
\text { Three meso-layers (1) } 0^{\circ} / 90^{\circ} / 0^{\circ} \text { are } \\
\text { composed by first-order lamellae in a } \\
+/-45^{\circ} \text { orientation (2). Each first-order } \\
\text { lamella consists of second-order } \\
\text { lamellae (3) which in turn consist of } \\
\text { single crystal third-order aragonite } \\
\text { lamellae (4). }\end{array}$ & 4 \\
\hline $\begin{array}{c}\text { Cortical Bone } \\
{[1]}\end{array}$ & 40 & $\begin{array}{l}\text { Collagen fibrils are reinforced by } \\
\text { hydroxyapatite nano-platelets (1) and } \\
\text { assemble into fibers (2) which are } \\
\text { arranged into lamellar sheets (3) which } \\
\text { are arranged concentrically into } \\
\text { Haversian systems (4) which are } \\
\text { arranged in parallel to the bone long } \\
\text { axes (5) }\end{array}$ & 5 \\
\hline $\begin{array}{c}\text { Antler Bone } \\
{[28,29]}\end{array}$ & 36 & $\begin{array}{l}\text { Structure similar to cortical bone but } \\
\text { less mineralized. }\end{array}$ & 5 \\
\hline
\end{tabular}


Table 2: Characterization of biological materials via indentation. For brief descriptions of the materials structures please see Table 1 .

\begin{tabular}{|c|c|c|c|c|}
\hline Material & $\begin{array}{l}\text { Level of } \\
\text { hierarchy } \\
\text { tested }\end{array}$ & $\begin{array}{l}\text { Elastic } \\
\text { modulus [GPa] }\end{array}$ & $\begin{array}{l}\text { Hardness } \\
\text { [GPa] }\end{array}$ & $\begin{array}{l}\text { Toughness } \\
{\left[\mathrm{MPa}^{*} \mathrm{~m}^{1 / 2}\right]}\end{array}$ \\
\hline Nacre & $\begin{array}{l}\text { 2: staggered } \\
\text { platelet } \\
\text { arrangement }\end{array}$ & $\begin{array}{l}30-120 \\
{[21,30-32]}\end{array}$ & $\begin{array}{l}0,5-8 \\
{[21,30-32]}\end{array}$ & $\begin{array}{l}6,8 \\
{[32]}\end{array}$ \\
\hline \multirow[t]{3}{*}{ Enamel } & 0 : single crystals & $40-115$ [19] & & \\
\hline & $\begin{array}{l}\text { 1: nano-fiber } \\
\text { arrangement } \\
\text { ('intra-rod') }\end{array}$ & 120 [19] & & \\
\hline & 2: multiple rods & $80-82[19,32,33]$ & $2,5-4[33,34]$ & $0,5-1,3[32]$ \\
\hline \multirow[t]{2}{*}{ Sponge Spicule } & $\begin{array}{l}\text { 1: nano-sphere } \\
\text { arrangement } \\
\text { (single } \\
\text { concentric layer) }\end{array}$ & $42-43[24]$ & $4,2-4,4[24]$ & \\
\hline & $\begin{array}{ll}2: & \text { layered } \\
\text { structure }\end{array}$ & $\begin{array}{l}41-42[24] \\
35[8]\end{array}$ & $\begin{array}{l}3,8-4,1[24] \\
2,5-3[8]\end{array}$ & $0,84[36]$ \\
\hline \multirow[t]{2}{*}{ Dentin } & $\begin{array}{l}\text { 2: intertubular } \\
\text { dentin network }\end{array}$ & $17-21[37]$ & $0,49-0,52[37]$ & $\begin{array}{l}\text { Material too soft } \\
\text { for indentation } \\
\text { toughness } \\
\text { measurements } \\
{[35]}\end{array}$ \\
\hline & $\begin{array}{l}\text { 2: peritubular } \\
\text { highly- } \\
\text { mineralized cuff }\end{array}$ & 29 [37] & $2,2-2,5[37]$ & \\
\hline Conch Shell & $\begin{array}{l}\text { 2: second-order } \\
\text { lamella structure }\end{array}$ & $60-100[38]$ & $3-6[38]$ & $\begin{array}{l}\text { Highly damaged } \\
\text { zone around } \\
\text { indents but no } \\
\text { well-defined } \\
\text { radial cracks for } \\
\text { toughness } \\
\text { calculations. } \\
\text { [39] }\end{array}$ \\
\hline \multirow[t]{2}{*}{ Cortical Bone } & $\begin{array}{l}\text { 4: single Osteon } \\
\text { lamellae }\end{array}$ & $\begin{array}{l}\text { Dry: } 22,5 \\
\text { Wet: } 18 \\
{[40,41]} \\
\end{array}$ & $0,4-0,6[40,41]$ & $0,5-2[42]$ \\
\hline & $\begin{array}{l}\text { 4: interstitial } \\
\text { lamella }\end{array}$ & $\begin{array}{l}\text { Dry: } 25,8 \\
\text { Wet: } 18 \\
{[40,41]}\end{array}$ & & \\
\hline Antler Bone & 4: lamellae & $5,5-7,6[43]$ & $0,16-0,21[43]$ & \\
\hline
\end{tabular}


Figure 1 displays material data determined in bending (due to a clear arrangement the data displayed is limited to this special type of loading). As bulk testing techniques encompass all hierarchical levels of a material, the available literature data was ordered by the authors according to hierarchy and is shown here as a function of the hierarchical levels of the specific materials. In Figure 1a, the elastic modulus is displayed normalized to mineral content and mineral particle modulus. From this plot it is obvious that elastic moduli decrease with increasing levels of hierarchy. Figure $1 \mathrm{~b}$ shows data for bending strength: interestingly all materials seem to fall within the same range of fracture stress except the sponge spicule - a material that is mainly loaded in bending during lifetime and thus, is optimized in resisting it [8]. Beside stiffness and strength, the mechanical parameter most often determined for biological materials is toughness. Values from single-edge notched bending (SENB) fracture resistance curve measurements are shown in Figure 1c and d. In Figure 1c initiation toughness values are shown ( $\mathrm{K}_{\mathrm{IC}}$ for $\Delta \mathrm{a} \rightarrow 0 \mathrm{~mm}$ ), whereas Figure 1d displays the degree of toughening which is the slope of a material's $\mathrm{R}$-curve, hence the increase in toughness $\Delta \mathrm{K}_{\mathrm{IC}}$ divided by the increase in crack length $\Delta \mathrm{a}$. Interestingly, the material with lowest amount of hierarchical levels - which is nacre - exhibits the highest initiation toughness values $[9,10]$. Cortical bone - the material with largest amount of hierarchical levels - exhibits smallest but also largest increase in toughening depending on the orientation tested [11]. 


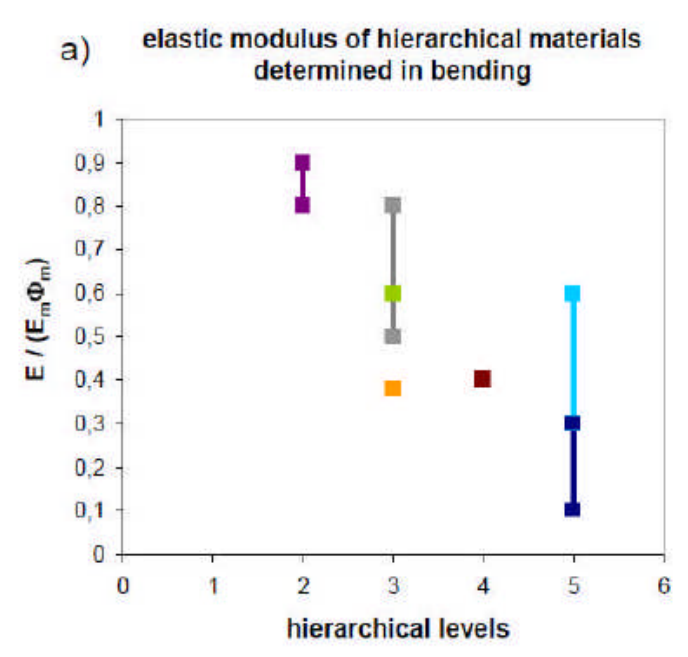

c) initiation toughness of hierarchical materials SENB data

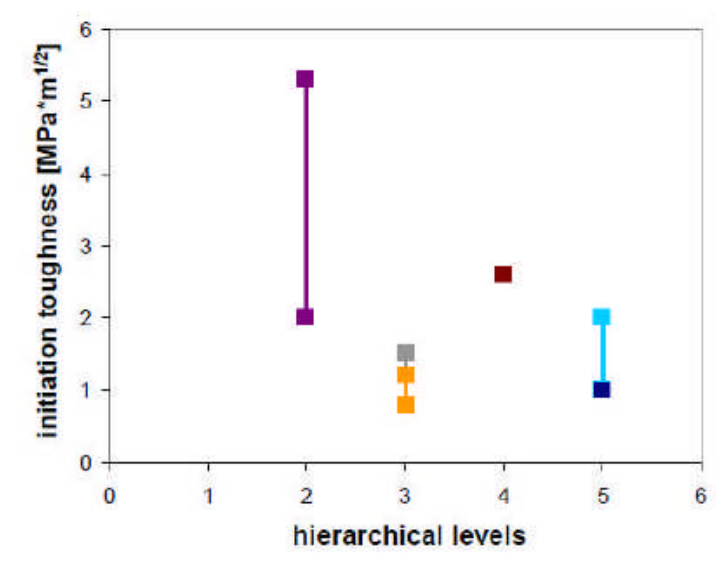

\begin{tabular}{|c|c|c|c|c|c|}
\hline nacre & enamel & sponge spicule & dentin & aconch & cortical bone \\
\hline
\end{tabular}

Figure 1: (a) Elastic modulus, (b) strength, (c) initiation toughness and (d) toughness increase for nacre, enamel, sponge spicule, dentin, conch shell, cortical and antler bone as a function of their hierarchical levels. All data was determined in bending and was taken from $[9,12,13,26,28,29,36,44,45-53,57]$. Large scattering of some values is due to different orientations and species tested and slight variations in experimental setup. Toughness and toughening values were extracted from SENB fracture resistance curve measurements. Initiation toughness values $\mathrm{K}_{\mathrm{I} 0}$ at the beginning of crack propagation $\left(\mathrm{K}_{\mathrm{IC}}\right.$ for $\left.\Delta \mathrm{a} \rightarrow 0 \mathrm{~mm}\right)$ are shown in c); toughening is defined as the slope of the fracture resistance curve, hence the increase in toughness $\Delta \mathrm{K}_{\mathrm{IC}}$ divided by the increase in crack length $\Delta \mathrm{a}$ and is shown in d).

The elastic modulus $\mathrm{E}$ displayed in a) is normalized due to elastic modulus of the basic mineral phase $\mathrm{E}_{\mathrm{m}}$ and its volume fraction $\varphi_{\mathrm{m}}$. 
Hierarchical biological materials are commonly said to be stiff, strong and tough $[2-4,12,13]-$ having a look at Figure 1, nacre is the material that fits best to this description. However, it is the material with lowest hierarchical structuring.

Also interesting concerning this point is a study that was recently published in Science [12]. The authors designed a material out of $\mathrm{Al}_{2} \mathrm{O}_{3}$ and PMMA which was in the broadest sense inspired by nacre (mineral platelets staggered within polymer, small amount of polymeric phase). With this material combination they even managed to exceed the toughness of nacre and reached values up to $30 \mathrm{MPa}^{*} \mathrm{~m}^{1 / 2}$ at crack extensions of $600 \mu \mathrm{m}$. So it seems as it is sufficient to have an efficient composite structure to influence properties as toughness and strength. But then the question arises - what are hierarchies in relation to mechanical properties good for and how are the mechanical properties at different length scales interconnected?

This is quite a difficult question not easy to answer but we are approaching a point in biomaterials research where this will be a central one. All experiments which could be conducted more or less easily are done: data from indentation and bulk testing are available for lots of materials, some of these data being summarized in this paper. Now, one further step should be to interconnect all these data and to conduct further systematic studies to get closer insights into the relation between hierarchical structuring and mechanical properties.

At the moment there are basically two investigations published to our knowledge which head towards this direction: the theoretical mechanical model developed by Gao and co-workers [14-18] and the experimental study from Ang et al [19]. Ang et al [19] conducted bulk compression and indentation experiments of dental enamel samples to determine elastic modulus and the elastic/inelastic transition ('yield strength') at all hierarchical levels of enamel. Gao and co-workers [14-18] developed a theoretical model by applying fracture mechanics concepts to a self-similar bone virtually loaded in tension to derive formulas for elastic modulus, strength, toughness and optimum structural sizes as a function of hierarchy. In order to get closer insight into the effects of hierarchical structures on the mechanical properties we proceed as follows: The literature data from figure 1 is the basis to compare these results with the theoretical model developed by Gao and co-workers [14-18] in section 2. Therefore, the model will be applied for the first time to calculate strength and elastic modulus values for existing biological materials. In section 3 , this mechanics model is used to analyze the experimental work of Ang et al [19] in more detail. 


\section{Hierarchical Mechanics Model due to Huajian Gao}

Huajian Gao and co-workers developed a mechanical model for a self-similar bone loaded in tension to calculate stiffness, toughness, strength, and optimum structural sizes at each level of hierarchy. Details can be found in [14-18] as only a short overview will be given here. Figure 2 visualizes the basic concept: the self-similar bone is thought to be built of hard mineral platelets (dark grey) enveloped by a soft protein matrix (bright grey) at the lowest hierarchical level (Figure 2a).
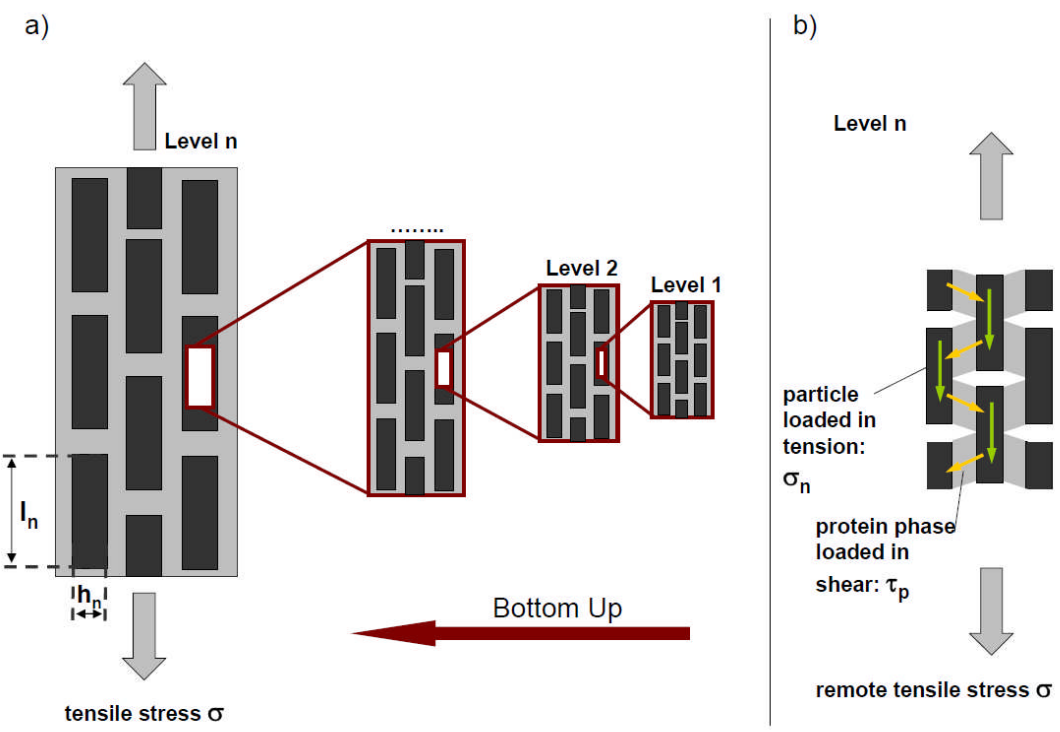

Figure 2: Self-similar bone loaded in tension according to Gao [14-18]. a) The model bone is composed of hard particles (dark grey) which are enveloped by a soft protein phase (bright grey) at each level. The composite structure at level $n$ forms the hard particles at level $(n+1)$. b) One basic assumption of this model is that hard particles carry the entire tensile load. The soft protein phase transfers the tensile load via shear to the particles. Tensile regions of the protein phase occurring between particles are neglected resulting in the so-called tensionshear-chain model illustrated here.

This composite further forms hard particles at the second level which again are enveloped by soft matrix. Hard particles of level 3 consist of composition 2 and so on. The total amount of hierarchical levels is $N$. The length of the hard particles is named $l_{n}$, the width $h_{n}$. The entire structure is virtually loaded in tension whereas it is assumed that the tensile load is carried 
totally by the hard particles (Figure $2 b$ ). The soft protein phase transfers the tensile load via shear to the particles. Geometric considerations yield:

$\sigma_{m}=\rho_{n} \tau_{p}$

where $\sigma_{\mathrm{m}}$ is the maximum tensile stress within the hard particles, $\rho_{\mathrm{n}}$ is the hard particle aspect ratio $\rho_{n}=l_{n} / h_{n}$ and $\tau_{p}$ is the shear stress within the soft protein phase.

The average stress within the composite at level $(n+1)$ can thus be calculated due to:

$\sigma_{n+1}=\frac{\sigma_{n} \varphi_{n}}{2}=\frac{\tau_{p} \rho_{n} \varphi_{n}}{2}$

With $\sigma_{\mathrm{n}}$ being the average tensile stress within the hard particles $\left(\sigma_{\mathrm{n}}=1 / 2 \sigma_{\mathrm{m}}\right)$ in the longitudinal direction, $\varphi_{\mathrm{n}}$ being the hard particle volume fraction, $\rho_{\mathrm{n}}$ being the aspect ratio, and $\tau_{\mathrm{p}}$ being the shear stress within the protein phase. The strength $S_{\mathrm{n}+1}$ of the material at hierarchical level $n+1$ is thus determined either by the shear strength of the soft protein phase $S_{p}$ or by the hard particle tensile strength $S_{n}$ :

$S_{n+1}=\min \left(\frac{S_{p} \rho_{n} \varphi_{n}}{2}, \frac{S_{n} \varphi_{n}}{2}\right)$

Note that here "protein failure" incorporates both protein-mineral interface and cohesive protein failure [14].

One basic assumption of Gao and co-workers is that structures of biological hierarchical materials are optimized primarily to exhibit superior mechanical properties. As a consequence they calculate optimum geometric structures by implying beneficial mechanical behaviour: for example, by assuming simultaneous failure of particles and protein which would exploit strength properties of both material phases best an optimum aspect ratio is calculated due to

$$
S=\frac{S_{p} \rho_{n} \varphi_{n}}{2}=\frac{S_{n} \varphi_{n}}{2} \rightarrow \rho_{n}=\frac{S_{n}}{S_{p}}
$$

The particle width $h_{n}$ of each level is calculated according to the Griffith criterion whereby it is hypothesized that hard particles reach their theoretical strength at each level of hierarchy. This kind of optimization results in a flaw tolerant material that is insensitive to cracks at all length scales - even up to the metre and kilometre range [17].

In contrast, our approach used here is to insert typical structural dimensions from existing biological materials to illustrate variances of mechanical properties with hierarchy.

Figure 3 illustrates the competition between particle and matrix failure due to equation (3). For our model calculations presented here, it was assumed that hard particles are enveloped by the same protein with shear strength $S_{p}=20 \mathrm{MPa}$ at each level of hierarchy and that hard particles are enveloped by the same amount of protein at each level, hence $\varphi_{n}=\varphi=0,95$. The 
overall mineral content $\Phi$ of the hierarchical material at level $\mathrm{n}$ can then be calculated with $\Phi$ $=\varphi^{\mathrm{n}}$ and hence, decreases with each additionally added hierarchical level. Hard particle strength at level 0 was chosen to be the theoretical strength of hydroxyapatite (HAP) or aragonite, $\mathrm{S}_{0}=\mathrm{E}_{\mathrm{HAP}, \mathrm{A}} / 10=8 \mathrm{GPa}[21,54]$. Hard particle aspect ratio was chosen to be 20 (bone [55]), 40 (nacre [22]), 100 and 1000 (enamel [55]) at the first hierarchical level and was further assumed to be constant.

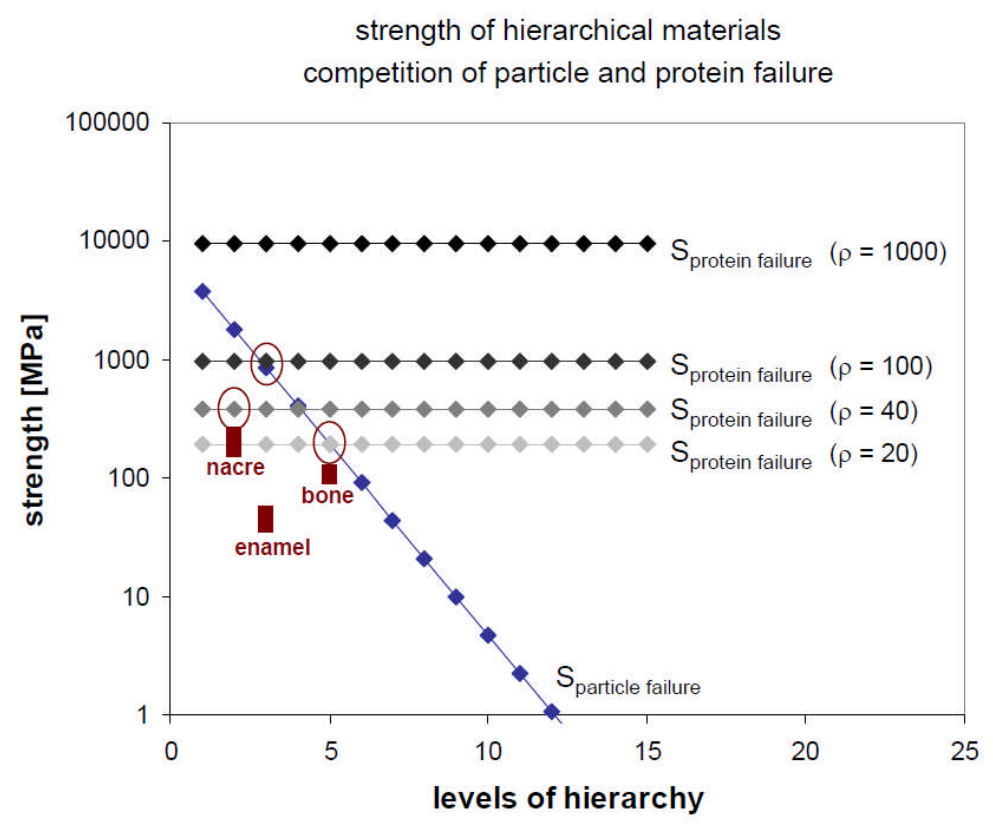

Figure 3: Strength of hierarchical materials due to equation (3), $S_{0}=8 \mathrm{GPa} ; \varphi_{\mathrm{n}}=\varphi=0,95 ; S_{\mathrm{p}}$ $=20 \mathrm{MPa}$. Experimental data is inserted as filled rectangulars and was taken from $[3,6,7,56]$ for nacre, enamel, and bone, respectively. According to theory, strength is determined either by protein or particle failure - depending on whether material phase fails first. Failure strength values predicted by theory for the three selected materials are encircled. For nacre ( $\rho$ $=40$ ), for example, failure should occur due to theory at $380 \mathrm{MPa}$ with protein failure being the decisive mechanism. In bone $(\rho=20)$ however, theory predicts simultaneous failure of matrix and protein at $190 \mathrm{MPa}$. For enamel $(\rho=1000)$ particle failure at $860 \mathrm{MPa}$ is predicted. Experimental values are in good agreement for nacre and bone whereas measured values for enamel (micro-tensile testing) are much lower than calculated ones.

As can be seen from Figure 3, matrix strength increases with increasing aspect ratio and remains constant for all levels of hierarchy. Particle strength, on the other hand, decreases with increasing hierarchical levels: Each additional level reduces the particle strength by half (equation 3). As a consequence, the failure mechanism for a self-similar hierarchical material with constant and medium particle aspect ratio would change from protein-failure to hard- 
particle failure at higher hierarchical levels as illustrated in Figure 3. For large aspect ratios (see for example $\rho=1000$ ), hard particle failure could even occur from the beginning on. Though this model calculation might be oversimplified (constant hierarchical aspect ratio determined by mineral platelet aspect ratio on level 1 , approximated mineral contents) to produce exact values for nacre, enamel and bone, failure competition can be illustrated using these three materials as an example. For nacre $(\rho=40)$, the model predicts protein failure at $380 \mathrm{MPa}$ - protein failure can indeed be observed during experiments with the mineral platelets remaining intact and being pulled out of the matrix [3]. Measured fractured values are around $170-230 \mathrm{MPa}$ [3] and hence, are a bit smaller than the calculated values. For enamel $(\rho=1000)$, the model predicts particle failure at $860 \mathrm{MPa}$. As enamel rods span the entire enamel layer they indeed have to be fractured if enamel is tested in tension parallel to the rods. However, strength values determined with micro-tensile techniques for enamel in this orientation range from 40-50 $\mathrm{MPa}[6,7]$ and hence, are much smaller than the theoretically predicted values. For bone $(\rho=20)$, Gao's optimization rule of simultaneous particle and protein failure is fulfilled: failure is predicted to occur at $190 \mathrm{MPa}$. Measured values for bone are around $100 \mathrm{MPa}[56]$ and hence, are a bit lower than the ones determined by the model calculation.

The elastic modulus can be calculated according to

$\frac{1}{E_{n+1}}=\frac{1}{\varphi_{n} E_{n}}+\frac{4\left(1-\varphi_{n}\right)}{\varphi_{n}^{2} \rho_{n}^{2} G_{n}^{p}}$

where $E_{n+1}$ is the elastic modulus at level $n+1$ which depends on the mineral content $\varphi$, hard particle aspect ratio $\rho$, hard particle elastic modulus $\mathrm{E}$ and protein shear modulus $\mathrm{G}$ of level $\mathrm{n}$. Figure 4 illustrates the influence of hierarchy on elastic modulus assuming that each additional level of hierarchy contributes with the same amount of protein, hence increasing the overall protein content. This assumption - which is used throughout this paper - seems to be quite reasonable as structural elements are most often enveloped by proteins on different size scales (for example within enamel, the HAP-nano-fibers as well as the micro-fibers (rods) are enveloped by proteins). Parameters for calculation were chosen to be $\rho=40, \varphi_{n}=\varphi$ $=0,95, \mathrm{G}_{\mathrm{p}} \sim \mathrm{E}_{\mathrm{p}} / 3 \sim 300 \mathrm{MPa}$ [3], $\mathrm{E}_{0}=80 \mathrm{GPa}$ [21,54]. For comparison, the experimental data for nacre, enamel and bone that was already displayed in Figure 1 is also inserted. The model calculation for a entirely self-similar material presented does not match completely the experimental data for all of these three materials as the aspect ratio was assumed to be 40 (the 
one for nacre) and the constant mineral volume fraction per hierarchy chosen does not match the exact mineral fractions of these materials, but the calculation confirms the trend from Figure 1a, namely that the elastic modulus decreases with every additional level of hierarchy being added. The calculation shows that this is mainly a consequence of the decrease in mineral content with increasing hierarchical structuring.

elastic modulus for hierarchical materials due to Gao

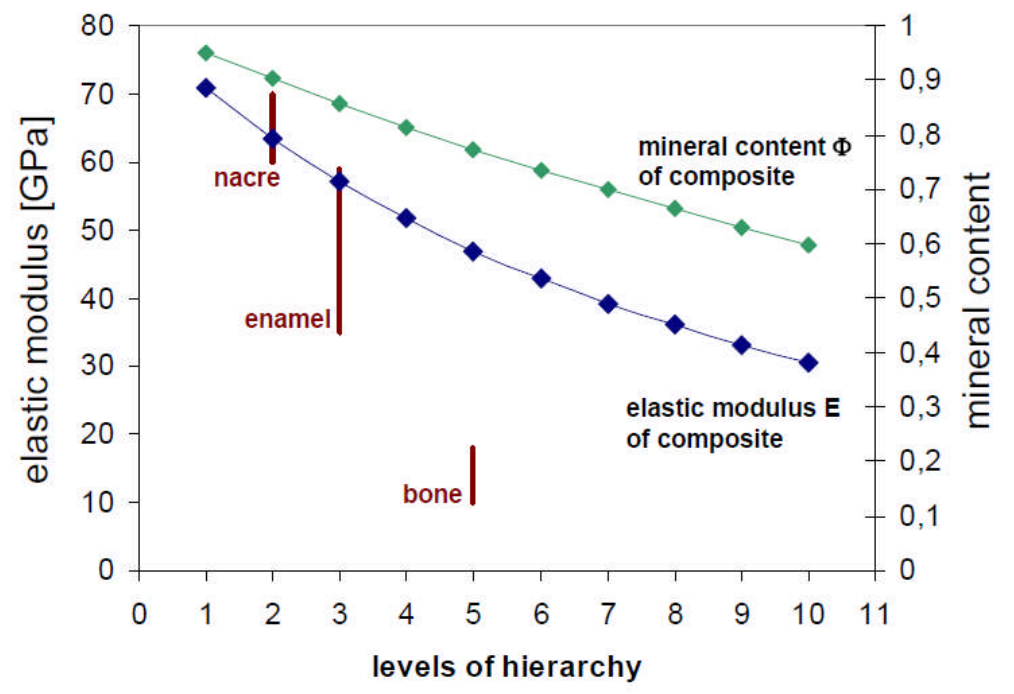

Figure 4: Elastic modulus of a self-similar hierarchical material with constant aspect ratio (Equation 5). Experimental data for nacre, enamel, and bone is inserted for comparison. Parameters used for calculation: $\rho=40 ; \varphi_{n}=\varphi=0,95 ; G_{p}=300 \mathrm{MPa} ; E_{0}=80 \mathrm{GPa}$.

The influence of mineral volume fraction and aspect ratio is illustrated in Figure 5. Therefore, the elastic modulus was calculated at level 1 with $\mathrm{G}_{\mathrm{p}} \sim \mathrm{E}_{\mathrm{p}} / 3 \sim 300 \mathrm{MPa}$ [3], $\mathrm{E}_{0}=80 \mathrm{GPa}$ [21,54], $\varphi=0,95 / 0,45 / 0,2$ and varying aspect ratio.

It can be seen from Figure 5 that hard particle elastic modulus $\mathrm{E}_{\mathrm{m}}$ and mineral content $\varphi$ determine the upper limit of the achievable elastic modulus $\left(=\varphi \mathrm{E}_{\mathrm{m}}\right)$. However, this limit can only be reached for large aspect ratios: the lower the mineral content the larger the aspect ratio has to be to reach this upper limit $\varphi \mathrm{E}_{\mathrm{m}}$. 
This means that elastic moduli in hierarchical materials can be tailored via a combination of both hard particle aspect ratio and hard particle volume fraction.

\section{elastic modulus due to Gao influence of aspect ratio}

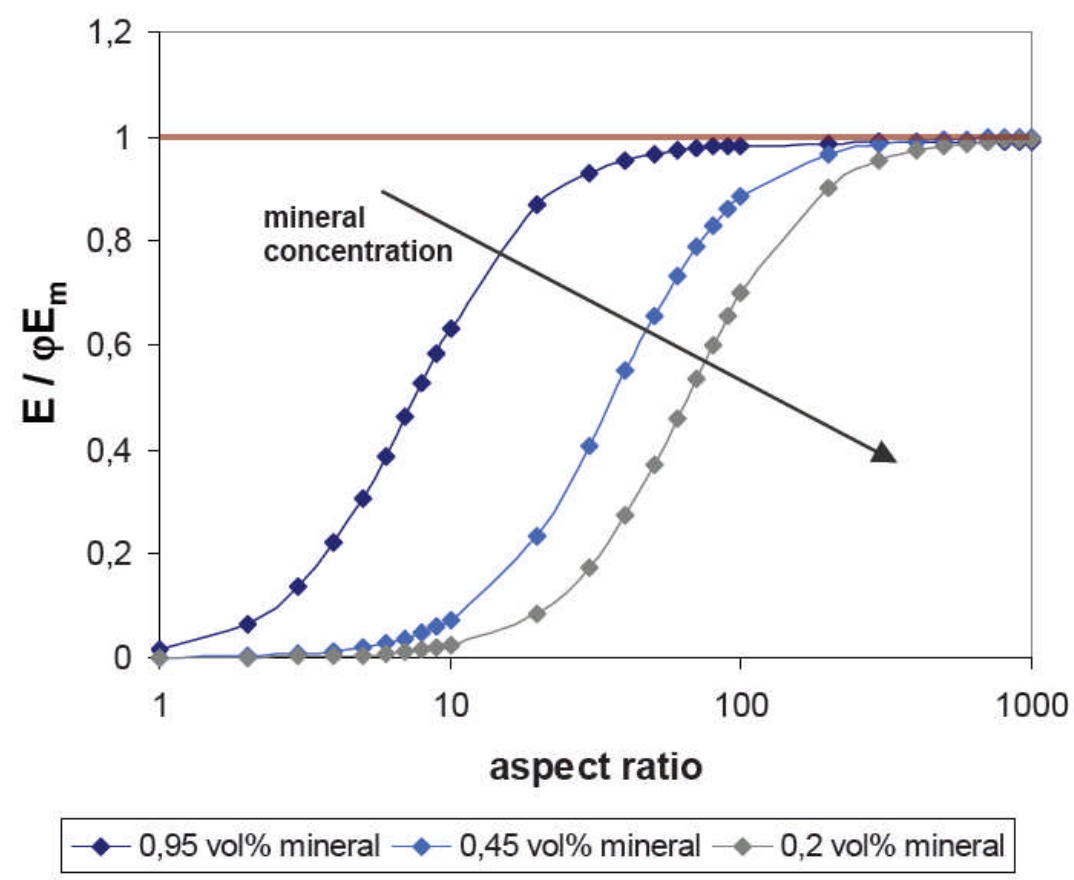

Figure 5: Influence of hard particle aspect ratio and mineral content on elastic modulus due to Gao.

The calculations for strength and elastic modulus are only a small extraction out of Gao's work. Further considerations for example concerning hierarchical toughness can be found in references [14-18] and shall be part of further research.

\section{Hierarchical Elastic Modulus and Strength for Enamel}

Ang et al [19] determined elastic moduli and elastic/inelastic transition ('yield strength') experimentally at all levels of hierarchy of dental enamel. Dental enamel covers the crowns of teeth and consists on the lowest level of HAP-nano-fibers of aspect ratio $\rho_{1}=2000\left(l_{1}=100\right.$ $\mu \mathrm{m}, \varnothing_{1}=50 \mathrm{~nm}$ [55]) which are enveloped by proteins. These nano-fibers are bundled 
together to micro-fibers (the so called "enamel rods") with aspect ratio $\rho_{2}=200\left(\mathrm{l}_{2}=1 \mathrm{~mm}\right.$, $\emptyset_{2}=5 \mu \mathrm{m}$ [23]). These rods are embedded within a protein-rich matrix that is reinforced by nano-HAP-crystallites [57]. The rods are relatively straight and parallel within the outer enamel region close to the tooth surface and are decussated or interwoven within the inner enamel region close to the dentin core of the tooth [23]. Within the inner enamel region, Hunter-Schreger Bands contain groups of rods of same orientation [23]. It is very likely that borders of Hunter-Schreger bands are also enriched with protein as the density of rods will be less at sites where orientation changes. Summarized, enamel can be described as a material consisting of three levels of hierarchy, namely: nano-fibers within protein that compose micro-fibers which are ordered into Hunter-Schreger bands (which - for simplicity - are assumed here to range the entire enamel layer $\rightarrow \rho_{3}=20$ with $1_{3}=1 \mathrm{~mm}, \emptyset_{3}=50 \mu \mathrm{m}$ ). Results for elastic moduli and yield strength of each level of hierarchy determined by compression testing and spherical indentation with different sized indenter tips [19] are displayed in Figure 6.

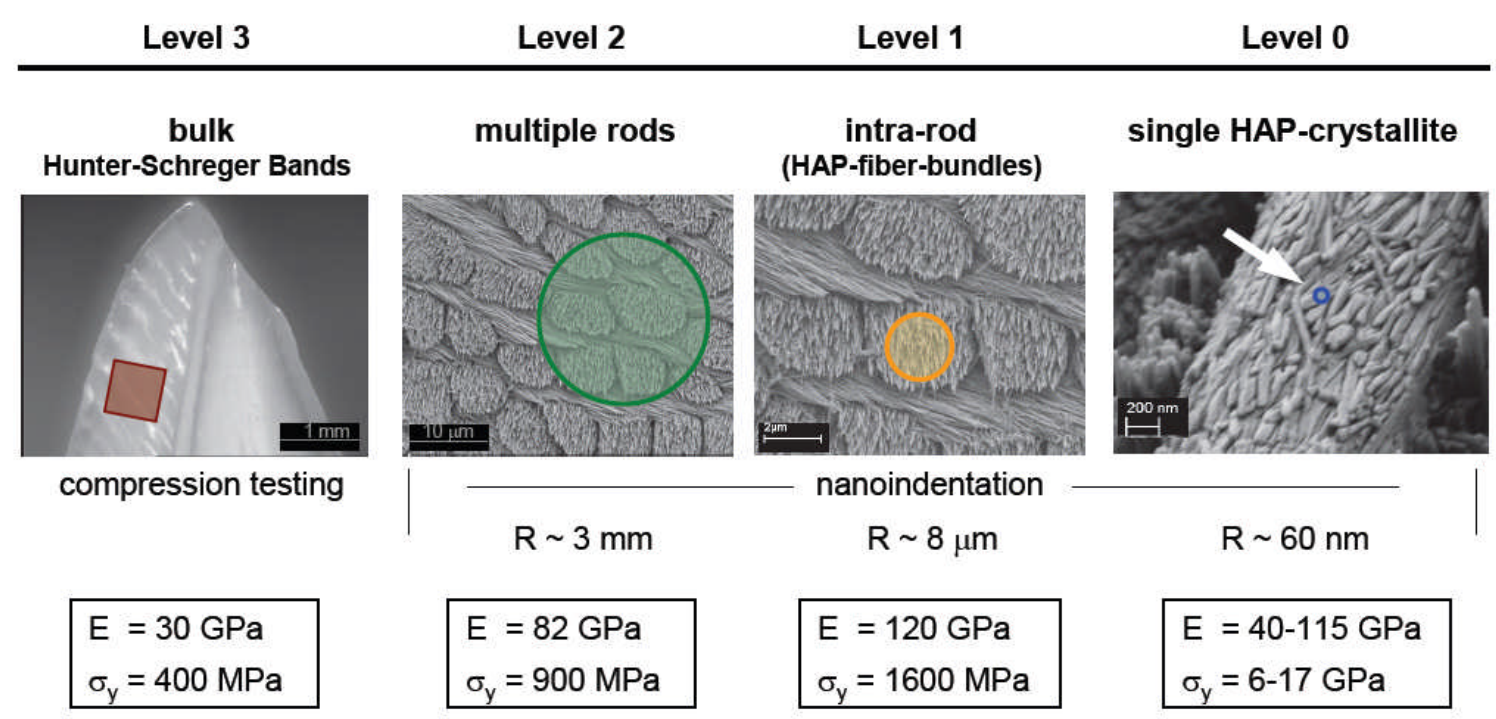

Figure 6: Elastic modulus and yield strength for enamel at all levels of hierarchy determined via compression and spherical indentation testing $(\mathrm{R}=$ spherical indenter radius). The entire study can be found in [19]. 
It was observed that both the elastic modulus as well as the elastic-inelastic transition decrease the more hierarchical levels are comprised by the testing technique. This is attributed to the increasing amount of proteins (with every additional hierarchical level one additional protein-rich interface is covered by the testing method) and the increasing amount of flaws (as for example interface cracks) that are involved in testing as the testing volume increases. Gao's theoretical model [14-18] is applied to these experimental results to study the influence of hierarchical structuring:

Figure 7 displays the elastic moduli determined by Ang et al [19] and values calculated due to Gao with the following parameters describing the enamel structure more precisely than the idealized parameters used in section 2: $\mathrm{E}_{0}=120 \mathrm{GPa}, \mathrm{G}_{\mathrm{p}}=300 \mathrm{MPa}, \varphi=0,95 \rightarrow \Phi=0,85$, $\rho_{1}=2000, \rho_{2}=200, \rho_{3}=20 . \mathrm{E}_{0}=120 \mathrm{GPa}$ was determined by Ang et al [19] for sintered HAP via nanoindentation.

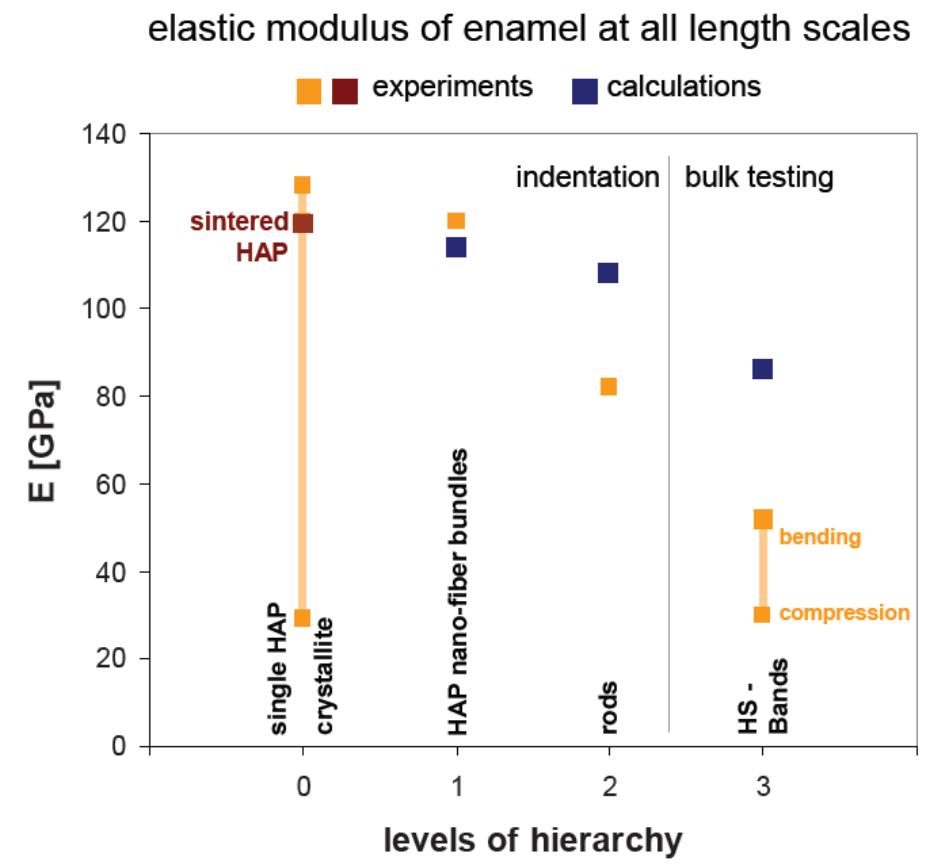

Figure 7: Experimental and theoretical elastic moduli for enamel at all length scale. Experimental data was taken from $[19,46]$, calculations were done according to Gao. For parameters used see text. 
Both experimental and calculated elastic moduli show the same trend that could also be obtained with the idealized calculations shown in section 2: elastic moduli decrease with increasing levels of hierarchy. Experimental and calculated values match best for the first hierarchical level (HAP nano-fiber bundles), whereas calculated values are a bit larger than experimental ones for levels 2 and 3. This might be due to the fact that the theoretical model does not incorporate material flaws as microcracks which are most probably incorporated in experimental testing.

The large variation of the experimentally determined modulus for a single HAP crystallite within enamel most likely arises from the fact that it is almost impossible to exactly indent one nanometre-sized HAP fiber - the smaller the measured values the more protein presumably is involved in the measurement. Therefore, $\mathrm{E}_{0}=120 \mathrm{GPa}$ was used for calculations (which was determined for sintered HAP via nanoindentation).

Figure 8 illustrates the calculated failure strength values for particle and protein failure as well as the experimentally determined yield strength values for all three hierarchical levels of enamel. For calculations, the following parameters were chosen: $\mathrm{S}_{0}=\mathrm{E}_{0} / 10=12 \mathrm{GPa}, \tau_{\mathrm{p}}=20$ MPa, $\varphi=0,95 \rightarrow \Phi=0,85, \rho_{1}=2000, \rho_{2}=200, \rho_{3}=20$. As samples are not fractured within nano-indentation measurements, the measured yield strength values are chosen as an indicator for strength which is no discrepancy with Gao's model. The equations developed by Gao are only valid within the elastic range of materials and hence, the failure strength calculated according to equation (3) might be the ultimate fracture strength but could also be the elastic limit, hence yield strength of a hierarchically material.

As can be seen from Figure 8, similar to elastic modulus, strength decreases with every additional level of hierarchy. At level 2 (rods), Gao's idealized failure mechanism of simultaneous particle and protein failure is nearly reached according to theory. Experimental values are a bit lower. Due to calculations, failure mechanisms change from particle failure at level 1 to protein failure at levels 2 and 3. This is in contrast to the simplified calculation presented in section 2 - which predicted particle failure at level 3. It shows that parameters inserted for calculations have to be chosen carefully. Unfortunately, a direct comparison of the theoretically predicted failure mechanisms and experiments is not possible as failure modes could not be determined in [19]. Nevertheless, it is quite impressive that calculations according to Gao's theoretical model which was originally developed for tension and a strictly self-similar material, yields reasonable results for elastic modulus and failure strength for 
enamel (section 3) and nacre (section 2) for different experimental testing techniques (bulk testing and indentation). Hence, the model can be used and is very helpful to obtain general trends to get insights into hierarchical structuring.

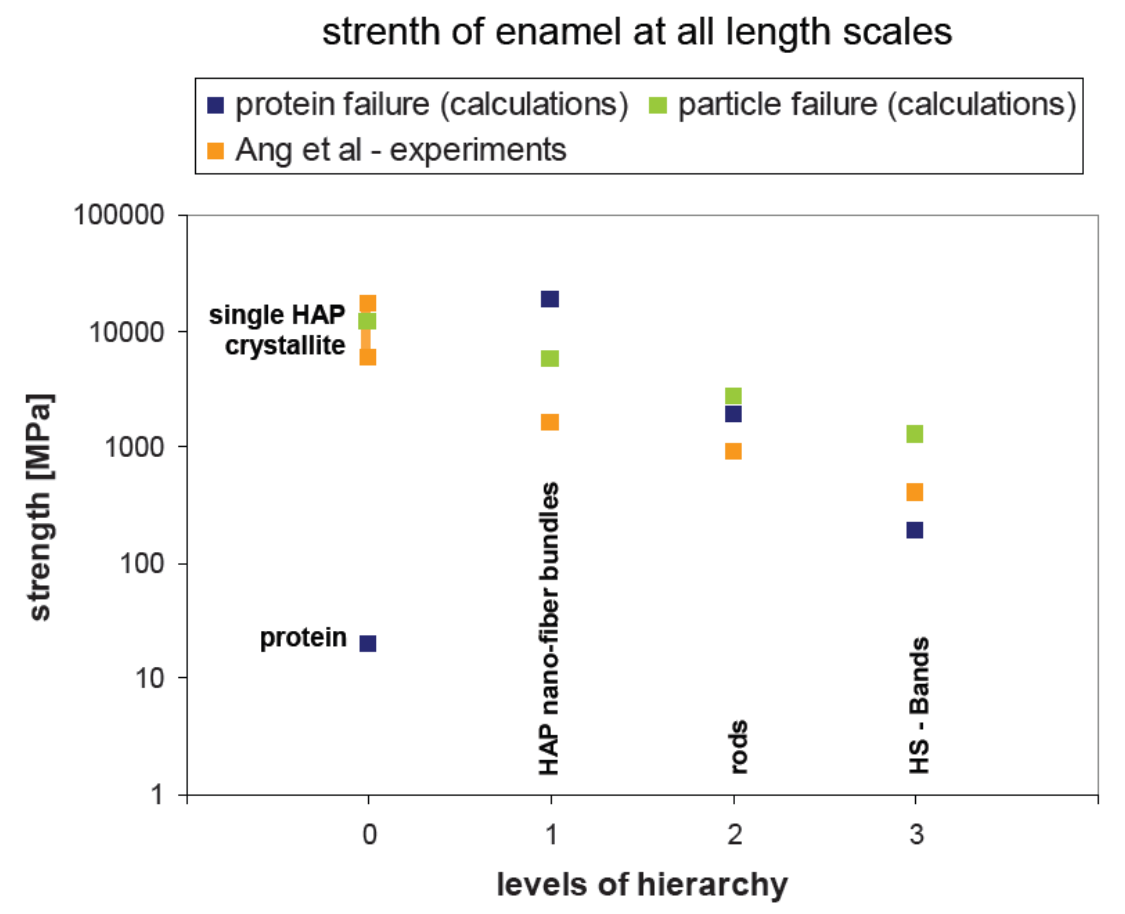

Figure 8: Experimental and theoretical strength for enamel at all length scale. Experimental data was taken from [13], calculations were done according to Gao. For parameters used see text. 


\section{Conclusion}

In this article the mechanical properties of hierarchically structured biological materials were analysed. Firstly, available experimental literature data was allocated according to the hierarchical levels included in mechanical testing. Secondly, it was demonstrated how the mechanics model developed by Huajian Gao and co-workers can be used to extract information about the mechanical properties at different hierarchical levels from these experimental data. Thirdly, the consistency of the theoretical model with experimental data was illustrated in detail by comparing calculated and experimental data for dental enamel on all three hierarchical levels enamel is built of. It could be shown that the strength of bone and enamel is close to Gao's flaw tolerant materials design, which postulates simultaneous particle and protein failure, whereas nacre seems to be protein failure controlled - the latter being in very good agreement with experimental observations. The model is capable to predict strength values for real biomaterials up to 5 hierarchical levels rather well. The elastic modulus is overestimated by the theoretical model after the second hierarchical level which is most probably due to existing cracks within the materials which are included in mechanical testing but not in the mechanics model.

\section{Acknowledgement}

Siang Fung Ang and Gerold A. Schneider gratefully acknowledge funding by the Deutsche Forschungsgemeinschaft. Gerold A. Schneider acknowledges the very fruitful discussions with Mike Swain.

Published in: Biomaterials, vol 31(25), 2010, 6378-6385

doi:10.1016/j.biomaterials.2010.05.044 
